\title{
BP Neural Network Model-based Urbanization Process Traditional Sports Cultural Development Exploration
}

\author{
Baijin Wang ${ }^{1, *}$, Xueheng $\mathrm{Li}^{2}$ and Yi Sun ${ }^{3}$ \\ ${ }^{1}$ Department of Physical Education, Chunchun Institute of Technology, Changchun 130012, Jinlin, China; ${ }^{2}$ Department \\ Plaaf Aviation University, Changchun 130000, Jilin, China; ${ }^{3}$ Institute of Physical Education, Jilin University, \\ Changchun 130012, Jilin, China
}

\begin{abstract}
World economy is in the trend of globalization while Chinese urbanization construction has also constantly developed. Nation has paid more and more attention to spiritual cultural construction and sports cultural construction. Nowadays, people sports consciousness strengthens, however it cannot speed up traditional sports events development, which attracts masses attention. The paper takes stilt race such traditional folk custom sports event as an example, starts from female performance and male performance the two aspects, utilizes BP neural network model to evaluate traditional folk custom sports event development conditions. Regard Guangdong, Hubei, Liaoning, Hebei and other eight provinces and cities data as sample data, make evaluation targeted at Shanghai, Chongqing, Tianjin and Chengdu four regions, the evaluation result shows that Shanghai, Chongqing traditional folk custom sports events are well developed.
\end{abstract}

Keywords: BP neural network, sports culture, stilt race, traditional sports, urbanization process.

\section{INTRODUCTION}

Urbanization process can improve people's living quality; international degree is also constantly growing. National people's interests on traditional sports are not so high while foreign sports events receive massive praises. Traditional sports cultural development is at the dilemma [1].

In 2011, Zhang Jia-Lin in the article " Poyang Lake surrounding area folk custom sports cultural investigation research", took Poyang Lake area folk custom sports development as research objects, regarded common civilian sports culture as starting point, applied multiple research methods, made research targeted at other regions characteristics, cultural concept, construction achievement and existing problems as well as other aspects [2], result showed that all levels' government personnel and common people still had shortage in cultural self-awareness aspect; Under the great background of market economy, due to people excessive pursuit of economy profits, traditional sports social value became deficient [3]. From the perspective of nation, government guiding on traditional folk custom sports was not enough; improper local policy document led to traditional folk custom sports development space to become little and little. With regard to this, the writer pointed out to take government as orientation, masses proactive cooperate and learn. Government should foster relative professionals so that explore helpful traditional folk custom cultural development management mode, positive guide masses to set up correct traditional sports cultural protection consciousness, proactive excavate traditional sports cultural resources on the premise not destroying others development and let its social values to be promoted. On the premise that respect and protect historical culture, took fully consideration of current sports culture, strived to combine the two so as to let people to better accept traditional sports $[4,5]$.

In 2013, Zhang Miao in the article " Jiangsu province folk custom sports development status, problem and situation research", emphasized Jiangsu province economic civilization belonged to leading level in the nation, however, in the aspect of traditional folk custom sports, its development status showed numerous contradictions [6-9]. The article comprehensive applied multiple research methods, made research targeted at traditional sports participation conditions, government organization, business joint performance and others multiple conditions, the result showed that from the aspect of gender, female participation conditions were better than that of male; from the perspective of age, old people participation degree was higher; from the perspective of participation purposes, building a strong body and mind was the important purpose. At present, traditional folk custom management mode was charged by government and coordinated by civil organization. Jiangsu province occupied certain advantages in folk custom sports athletics performance, but single development path still restricted its development [8]. With regard to this, the writer presented that government as main leading force; it should expand multiple development paths. Beyond that, Jiangsu province traditional sports development needed efforts from all classes in society, and formed into industry, agriculture, business, government joint cooperative mode.

In 2008, Pan Yi-He in the article " Small town residents participating in traditional festivals folk custom sports activities investigation and reflection", on the premise referencing 
Table 1. Stilt race $200 \mathrm{~m}$ man performance.

\begin{tabular}{|c|c|c|c|}
\hline \multicolumn{1}{|c|}{ Unit } & Nerformance(s) & 200m \\
\hline \multicolumn{2}{|c|}{} & \multicolumn{2}{|c|}{ Rank } \\
\hline \hline Guangdong1 & Tian Shi-Fen & 22.95 & 1 \\
\hline Hubei2 & Yang Wei & 23.29 & 3 \\
\hline Hubei3 & Yang Ming-Feng & 23.32 & 4 \\
\hline Liao ning4 & Yang De-Quan & 24.06 & 5 \\
\hline Hebei5 & Peng Li-Ming & 24.23 & 6 \\
\hline Hunan6 & Qin Hao-Bo & 24.54 & 7 \\
\hline Guangdong7 & Zhang Jia-Wu & 25.23 & 8 \\
\hline Guangxi 8 & Pan Shao-Jing & & 3 \\
\hline
\end{tabular}

Table 2. Stilt race $200 \mathrm{~m}$ woman performance.

\begin{tabular}{|c|c|c|c|}
\hline \multicolumn{4}{|c|}{$200 \mathrm{~m}$} \\
\hline Unit & Name & Performance(s) & Rank \\
\hline Hubei 1 & Zhang Min & 27.54 & 1 \\
\hline Hubei2 & Ren Yan-Ling & 27.94 & 2 \\
\hline Hebei3 & He Chun-Hua & 28.45 & 3 \\
\hline Ningxia4 & Na Dong-Mei & 28.54 & 4 \\
\hline Beijing5 & Chen Ju-Ming & 28.68 & 5 \\
\hline Guangdong6 & Tang $\mathrm{Na}$ & 28.77 & 6 \\
\hline $\mathrm{Hu}$ Nan7 & Zhang Yan-Qing & 29.04 & 7 \\
\hline Beijing8 & Zhang Qiao-Si & 29.04 & 8 \\
\hline
\end{tabular}

lots of document literature, took small town residents as research objects, started investigation on situations of their engagement in traditional folk custom sports, went deeper into exploration of the aspects that affected small town sports development, the result showed that female participation degree was obviously higher than that of male, differences in job nature, economic income could lead to traditional sports participation degrees differences [9]; All levels of people in the town basically came to terms in the thoughts of traditional sports and economy as well as spiritual construction relationships. Insufficient government support, deficient propaganda, insufficient capital investment, fewer sites and not high effectiveness of organizational activities as well as other issues restricted traditional sports development.

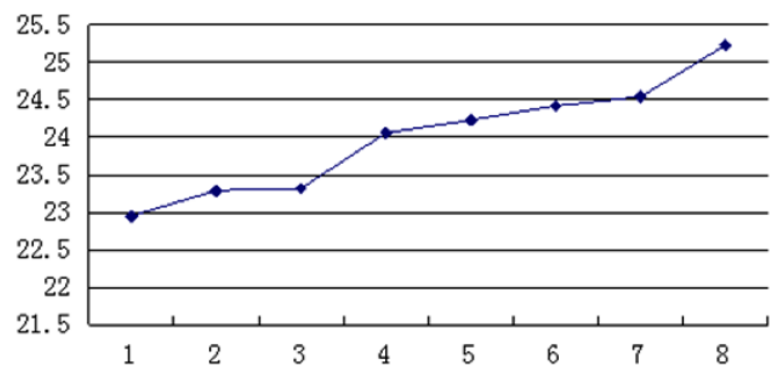

Fig. (1). Men's 200m tall horse performance comparison chart.
The paper will select stilt race as the representative of traditional folk custom sports events, comprehensive consider multiple aspects and make evaluation and researches on multiple provinces and cities.

\section{MODEL ESTABLISHMENT}

\subsection{Data Collection}

Tables $\mathbf{1}$ and $\mathbf{2}$ is original data table that comes from "Western Hubei circle folk custom sports inheritance and sustainable development research".

From Table 1, it is clear for us that Guangdong, Hubei and Liaoning three provinces have better stilt race single performance, and Hubei province two players' performances have no big differences. Eight athletes performances comparison is as Fig. (1).

From Fig. (1), We can see that mark number "4", "5" "6" 6 " are Liaoning, Hunan, Hebei, Guangdong four provinces men athletes performances rather approximate.

From Table 2, it is clear for us that in the aspect of woman stilt race, Hubei province, Hebei province, and Ningxia province performances are good, and Hubei province two athletes' performances have no big differences. Comparison figure is as Fig. (2). 


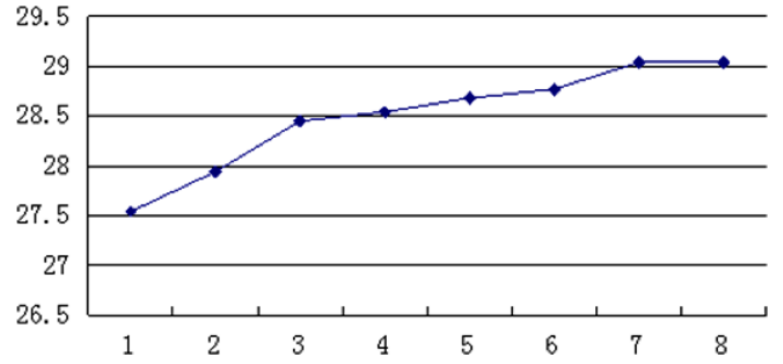

Fig. (2). Women's 200m tall horse performance comparison chart.

From Fig. (2), we can see that woman performance is obviously poorer than that of man. Mark number "3", "4" , "5" , "6"are Hebei, Ningxia, Beijing, Guangdong performances that are rather approximate.

\subsection{Data Reduction}

Due to we make evaluation on provinces, sort out provinces same man and woman performances together, in case that man and woman stilt race performances don't exist at the same time, value them (30s), regard the data after sorting as sample data.

Data in Table 3, for the same province occurred twice performances, all take average value. In order to clearly express sample data condition, draw Fig. (3).

From Fig. (3), we can see that Ningxia and Beijing the two cities man and woman performances have no big differences, other six provinces' man and woman performances' differences are bigger.

\subsection{Neural Network Model}

Neural network model is originated from neurobiology. Its computation process is similar to biology nerve cell reaction process, as Fig. (4).

In neural network, lots of different nerve cells included axon end can enter into the same nerve cell Dendron and form into a large number of synapses. All synapses of differ-

Table 3. Each province sample data.

\begin{tabular}{|c|c|c|}
\hline Province & Man & Woman \\
\hline \hline Guangdong1 & 23.745 & 27.74 \\
\hline Hubei2 & 23.305 & 30 \\
\hline Niaoning3 & 24.06 & 28.45 \\
\hline Hebei 4 & 24.23 & 29.04 \\
\hline Hunan5 & 24.42 & 30 \\
\hline Guangxi6 & 25.23 & 28.54 \\
\hline Ningxia7 & 30 & 30 \\
\hline Beijing8 & 28.86 & 2 \\
\hline
\end{tabular}

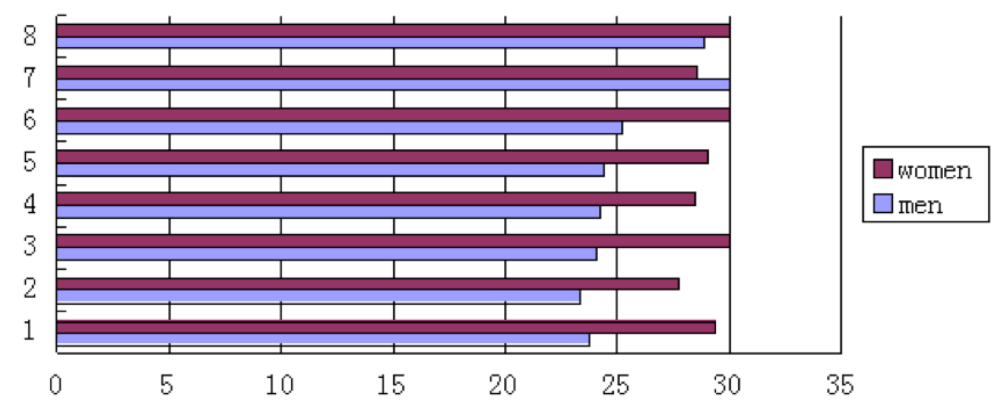

Fig. (3). Sample data case diagram.

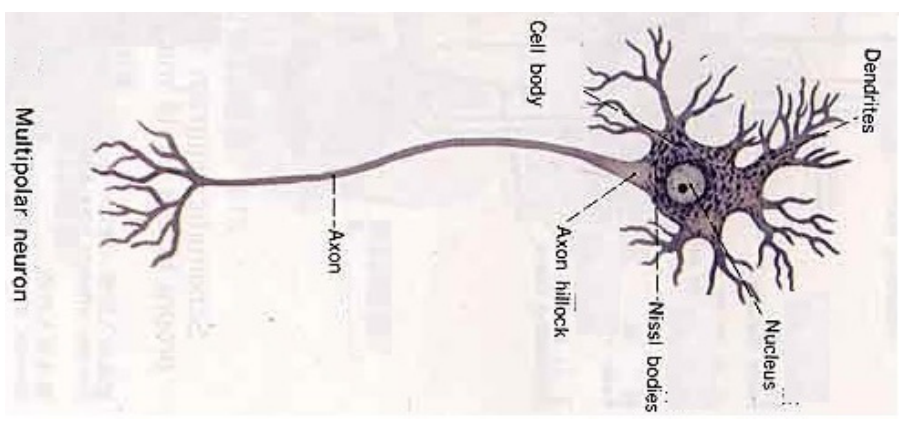

Fig. (4). The structure of neurons. 
ent origins released neurotransmitters can exert on same nerve cells' membrane potential changes. Thereupon, nerve cells space comprehensive information ability that is nerve cell can integrate input information of different origins in Dendron. Base on the ability, people simulate nerve cell reaction process and create artificial nerve cell model, as Fig. (5) shows, symbols definition in figure is as Table $\mathbf{4}$ shows.

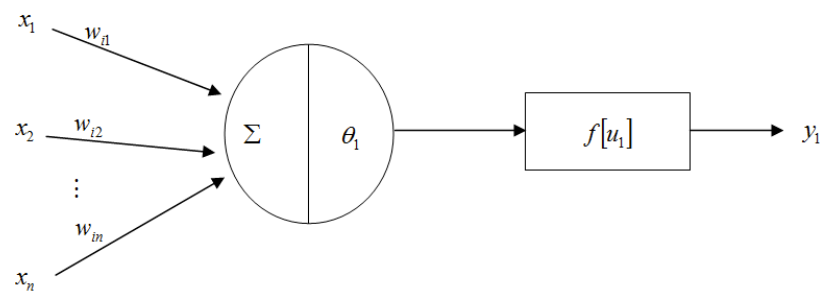

Fig. (5). The schematic of mathematical models of neurons.

Table 4. Mathematical model's symbol definition.

\begin{tabular}{|c|c|}
\hline Symbol & Definition \\
\hline \hline$x_{1}, x_{2}, \cdots, x_{n}$ & $\begin{array}{c}\text { Nerve cell input part that is information released } \\
\text { by previous level }\end{array}$ \\
\hline$\theta_{i}$ & Nerve cell threshold value \\
\hline$y_{i}$ & Nerve cell output \\
\hline$f\left[u_{1}\right]$ & Excitation function \\
\hline
\end{tabular}

$f\left[u_{1}\right]$ Decides that output form that arrives at threshold value $\theta_{i}$ under common effects of inputting $x_{1}, x_{2}, \cdots, x_{n}$. Fig. (6) shows two kinds of excitation functions images. The paper adopted models use the second kind excitation function.
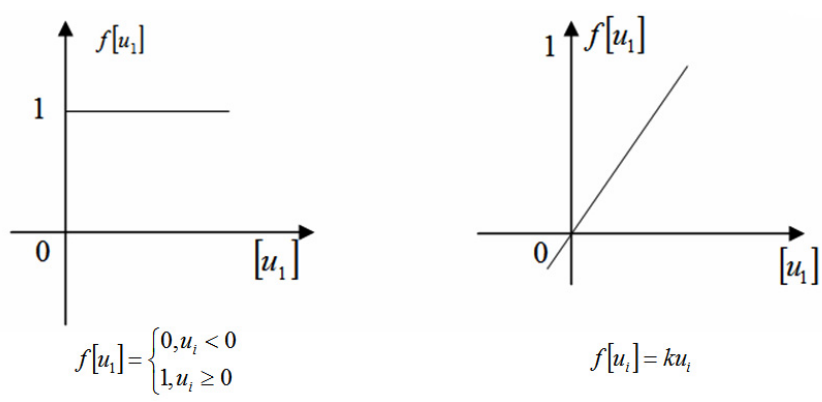

Fig. (6). Typical excitation functions.

Among them ,

$u_{i}=\sum_{j} w_{i j} x_{i}-\theta_{i}$

So

$y_{i}=f\left[u_{i}\right]=f\left(\sum_{j} w_{i j}-\theta_{i}\right)$

Formula (2) is individual nerve cell full mathematical model expression.
Neural network is a kind of multiple layer forward network, adopts minimum mean square error computational way. When apply counter propagation algorithm into feed forward multiple network, utilize Sigmoid as excitation function, use following steps to make recursion solving on $w_{i j}$ that is network weight coefficient. In case every layer has $\mathrm{n}$ pieces of nerve cells, for the $\mathrm{k}$ layer the i nerve cell , then it has $\mathrm{n}$ pieces of weight coefficients $w_{i 1}, w_{i 2}, \cdots, w_{j n}$. In addition, select one more $w_{j n+1}$ to express $\theta_{i}$. When input sample $x$, take $x=\left(x_{1}, x_{2}, \cdots, x_{n}, 1\right)$.

1) Align value to $w_{i j}$. To every layer $w_{i j}$, align a very little nonzero random number, and meanwhile $w_{j n+1}=-\theta_{i}$ 。 Due to the model utilizes Matlab to operate, the alignment process is computer's random process, and just because of that, same programming codes in different running processes, the results may appear differences.

2) Input sample value $x=\left(x_{1}, x_{2}, \cdots, x_{n}, 1\right)$, and corresponding expected output $y=\left(y_{1}, y_{2}, \cdots, y_{n}, 1\right)$.

3) Calculate each layer output, for the k layer the i nerve cell output $x_{i k}$, it has

$y_{i}^{k}=f\left\lfloor u_{i}^{k}\right\rfloor$

Among them,

$u_{i}^{k}=\sum_{j} w_{i j} x_{j}^{k-1}-\theta_{i}^{k}$

In formula, $x_{n+1}^{k-1}=1, w_{i(n+1)}=-\theta$

4) Solve each layer computation error $d_{i}^{k}$, for output layer, it has $k=m$, then it has

$d_{i}^{m}=x_{i}^{m}\left(1-x_{i}^{m}\right)\left(x_{i}^{m}-y_{i}^{m}\right)$

For other layer, it has

$d_{i}^{k}=x_{i}^{k}\left(1-x_{i}^{k}\left\{\sum_{j} w_{i j} x_{j}^{k-1}-\theta_{i}^{k}\right)\right.$

5) Correct $w_{i j}$ and $\theta_{i}$, it has

$w_{i j}(t+1)=w_{i j}(t)-\eta d_{i}^{k} x_{j}^{k-1}$

6) After solving each layer each weight coefficient, it can judge whether it conforms to requirements according to established criterion. If it don't conform, then return to the step 3 , on the contrary, end computing.

\subsection{Computing and Computed Result}

In latlab running program codes, regard the program running selective training error being $10^{-2}$ as stop calculation 
Table 5. Evaluation objects data.

\begin{tabular}{|c|c|c|}
\hline City & Man & Woman \\
\hline \hline Shanghai & 23.45 & 27.96 \\
\hline Chongqing & 23.86 & 29.35 \\
\hline Tianjin & 27.85 & 28.78 \\
\hline Chengdu & 29.32 & 28.87 \\
\hline
\end{tabular}

condition. Due to stilt race performances are between 20 and 30 , selected stop calculation conditions are proper. In following schematic figure, “*” represents stilt race worse performances areas, "o" represents stilt race better performances areas.

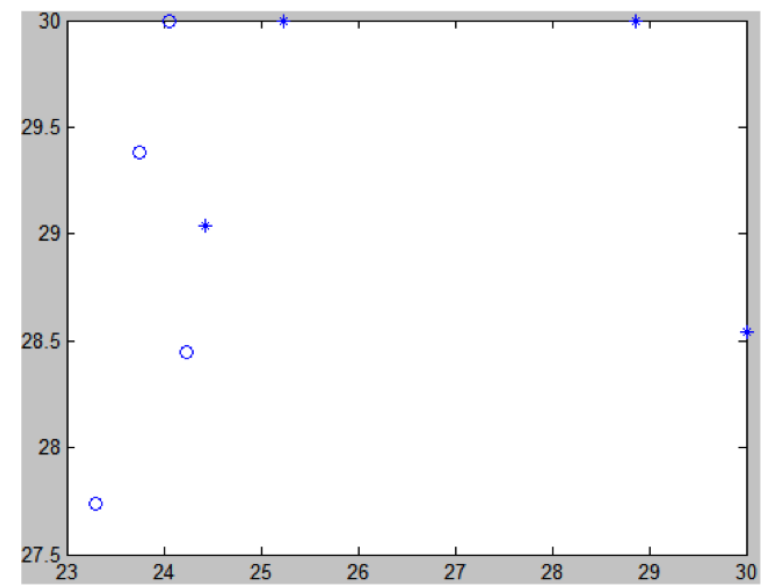

Fig. (7). Distribution of work results in two regions.

From Fig. (7), we can see that good performance area and poor performance area have boundary, according to the distribution conditions, we can define discriminate straight line $(24.3,27.5),(24.6,31)$.

Objects under evaluation are Shanghai, Chongqing, Tianjin and Chengdu. In Table 5, it lists out data after sorting so that detail research on the process.

Use Matlab software to program data in Table 5, it can get result as Fig. (8).

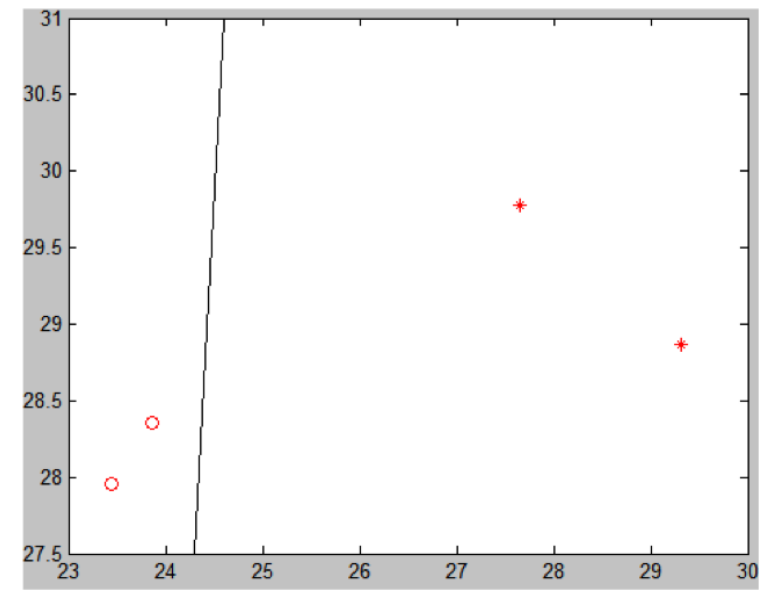

Fig. (8). The schematic of discrimination results.
From Fig. (8), it is known for us that Shanghai and Chongqing two cities' are excellent cities in stilt race sports event, Tianjin and Chengdu are cities of poor development in stilt race sports event.

\section{CONCLUSION}

Neural network implements reflection process from input information to output result. Neural network has ability of handling with multiple kinds of input information; it lets complicated problems to be simple and easier operating in solving process. However, if there is a large number of data to be analyzed, neural network may not truly reflect practical status due to too much computation process. In addition, neural network should reasonable estimate training errors, once the error estimation is improper, it may occur to computed result incorrect.

The paper applies neural network model in researching on stilt race sports event development degrees issue, by established model computing, it is clear that Shanghai and Chongqing two cities' are cities of better development in stilt race sports event, Tianjin and Chengdu are cities of worse development in stilt race sports event. Combine with practical conditions; it is easier to find that obtained conclusions conform to practice. Shanghai and Chongqing are directcontrolled municipalities, spiritual civilization construction is rather perfect, and emphasis on traditional culture is higher, which is helpful for stilt race sports event development.

\section{CONFLICT OF INTEREST}

The authors confirm that this article content has no conflict of interest.

\section{ACKNOWLEDGEMENTS}

This work is supported by the Key Project of Guangxi Social Sciences, China (No. gxsk201424), the Education Science fund of the Education Department of Guangxi, China (No. 2014JGA268), and Guangxi Office for Education Sciences Planning, China (No. 2013C108).

\section{REFERENCES}

[1] L.U. Xu-tao, and H. Hong, "Survival and development of national traditional sports major under the background of globalization", Journal of Chengdu Physical Education Institute, vol. 37, no. 9, pp. 78-80, 2011.

[2] J. Zhao, "On the modernization dispute of national traditional sports", Sports Sciences Researches, vol. 15, no. 3, pp. 14-17, 2011. 
[3] X-W. YE, "The cultural ecological perspective of heritage of national traditional sports", Bulletin of Sport Science \& Technology, vol. 19, no. 1, pp. 112-113, 2011.

[4] J. Zhao, and J. Wang, "Exploration of the way to the inheritance and development of traditional national sports", Journal of Physical Education, vol. 16, no. 8, pp. 93-95, 2009.

[5] R. Li, and C. Yu, "Sports globalization and descent of China traditional sports, Sports Culture Guide, vol. 4, pp. 84-86, 2007.

[6] L. Chen, "The research status and prospects of sport globalization at home and abroad", Sports \& Science, vol. 30, no. 4, pp. 54-56, 2009.
[7] L. Guo, "Studies of the ways of inheriting and passing on of the ethnic traditional sports in China", Journal of Southwest China Normal University (Natural Science), vol. 33, no. 6, pp. 157-160, 2008.

[8] Y. Hu, "Cultural confusion and coping mechanism of martial arts in context of globalization", Journal of Shenyang Sport University, vol. 28 , no. 4, pp. 110-113, 2009.

[9] G. Wang, "Concerns of national traditional sports: current status, problems and reflections", Journal of Capital College of Physical Education, vol. 20, no. 2, pp. 1-4, 2008.

Received: June 10, 2015

(C) Wang et al.; Licensee Bentham Open.

This is an open access article licensed under the terms of the (https://creativecommons.org/licenses/by/4.0/legalcode), which permits unrestricted, noncommercial use, distribution and reproduction in any medium, provided the work is properly cited. 